\title{
Потенциал функционирования платежно-расчётной системы в рамках ЕАЭС и обращения коллективной валюты
}

Достаточным условием функционирования модели региональных расчётов и переводов является наличие базовых межгосударственных соглашений, предоставляющих право международным операторам платежных систем - VISA, Mastercard и др. - учитывать операции по трансграничным переводам денежных средств между резидентами и нерезидентами. Такие соглашения не требуют сложных форм интеграции, таких как валютный союз в зоне евро.

Например, глобальная система расчётов СВИФТ работает на базовых принципах открытости экономик, либерализации сделок по текущим операциям, трансграничного движения капитала, членства в ведущих международных финансово-экономических организациях. Поэтому в системе СВИФТ участвует подавляющее большинство стран, несмотря на отсутствие глобальной зоны свободной торговли и прочих форм глубокой интеграции.

Однако дополнительное условие по наличию коллективной денежной единицы требует более высоких фрорм интеграции, поскольку в этом случае система вступает в сфреру интересов суверенного государства: эмиссия интернациональных денег, независимая кредитно-денежная политика, самостоятельная валютная политика, суверенные фонды финансовой стабильности. Так, коллективная валюта ЭКЮ начала фрункционировать в рамках экономического союза стран-членов ЕС и Европейской валютной системы, которые предшествовали этапам высшей формы интеграции в виде валютного союза, банковского союза, фискального союза, долгового союза, политического союза. Для финансовой интеграции необходимо заключение соответствующих соглашений по всем перечисленным фрормам региональной интеграции [1].

Некоторые специалисты отмечают особое условие фрункционирования единой валюты, которое предполагает первоначальное образование политического союза перед непосредственным запуском в обращение единой валюты, поскольку обращение любых денег требует наличия безусловного центра принятия решений об интервенции, эмиссии, установления процентных ставок, операций на открытом рынке. Функционирование валютного союза с коллективной валютой без политического союза обеспечивает независимость стран-членов в эмиссии денег в пределах, в которых правительство конкретной страны считает необходимым обращения денег для удовлетворения своих потребностей в ущерб принципа солидарности на уровне наднационального регулирования [8].

\section{Факторы создания и функционирования платежно-расчётной системы в рамках ЕАЭС}

Одна из декларируемых целей ЕАЭС - укреплять и интенсифицировать интеграционные процессы через общий рынок капиталов, общую платежно-расчётную систему, общую систему кредита, общий рынок долгов [5].

Важнейшим условием создания и функционирования эффективной модели региональной системы расчётов с использованием коллективной денежной единицы является глубокая региональная экономическая интеграция стран на высоких ступенях, в виде сложных форм организации. Предполагается, что к моменту начала создания такой модели страны группировки уже прошли этапы преференциальных соглашений, переросли зону свободной

\author{
(C) Жариков М. В., 2021
}

ЖАРИКОВ Михаил Вячеславович, д-р әкон. наук, профессор департамента мировых фринансов факультета международных экономических отношений Финансового университета при Правительстве Российской Федерации (г. Москва). E-mail: michaelzharikoff@gmail.com 
торговли, вышли за рамки договоренностей по таможенному союзу, сформировали и закрепили принципы функционирования единого, или общего, рынка, заключили соглашение о единой политике на правах экономического союза [13].

Ещё одним важным условием модели региональных расчётов с использованием коллективной денежной единицы является степень завершенности каждого из этапов интеграции. Условным критерием завершенности или незавершенности можно считать наличие барьеров и ограничений различного характера по всем сорерам взаимодействия, сотрудничества, экономической и таможенной политики стран интегращионного блока. По данным Евразийской экономической комиссии, на уровне ЕАЭС действует 58 препятствий, в т.ч. 11 барьеров, 13 изъятий и 34 ограничения. Кроме того, препятствия имеются и на уровне каждой из стран-членов, число которых превышает 200 единиц ${ }^{\mathbf{1}}$. Наличие большого количества препятствий говорит о незавершенности фрормирования как таможенного, так и экономического союза. Некоторые барьеры в ЕАЭС не удовлетворяют условиям зоны свободной торговли.

На уровне ЕАЭС нет единого документа о взаимном признании электронной подписи, что является принципиальным моментом, исходным пунктом формирования платежной системы. Также на уровне ЕАЭС отсутствует возможность использовать банковские гарантии, выдаваемые банками-резидентами одной страны-члена, под обеспечение заявок для участия в госзакупках и обеспечение процедуры выполнения условий контракта (договора) в процессе осуществления госзакупок стороной заказчика другой страны-члена [6].

Наличие протекционистских ограничений в данных секторах экономического союза говорит о том, что страны-члены опасаются потерять суверенитет в банковской, финансовой сфере и киберпространстве, видят потенциальные угрозы использования одной страны-члена методов или инструментов, которые позволяют формировать конкурентные преимущества в ущерб другой страны-члена [2].

\section{Анализ барьеров,}

\section{образуемых разноуровневым развитием экономик ЕАЭС}

Основные проблемы при формировании модели единых платежно-расчётных отношений в рамках интеграционных объединений, согласно опыту фрункционирования аналогичной системы в зоне евро, вызваны дивергенцией участников ЕАЭС по основным индикаторам системы национальных счетов. Так, несмотря на некоторую стабилизацию в странах ЕАЭС после рыночных реформ, гиперинфляции 90-х гг. уровни цен, ставки налогов, кредитов достаточно сильно отличаются друг от друга. Существенная дивергенция препятствует построению общего тренда при оценке возможностей гармонизации [4]. Страны ЕАЭС переживают условия нестабильности, находятся под влиянием международных санкций, неблагоприятной внешнеәкономической конъюнктуры, в результате чего образуется сильная вероятность бифуркации динамики ведущих макропоказателей [7; 14].

Корреляционный анализ основных макропоказателей показывает слабую связь динамики траекторий развития стран ЕАЭС, за исключением корреляционной зависимости по ставкам кредита стран ЕАЭС, которая практически во всех наблюдаемых случаях превышает 0,7 , что говорит о сильной степени корреляции между странами ЕАЭС (cл. табл. 1-3). Однако основной вывод с учетом других ведущих макроэкономических показателей в этом отношении состоит в недостаточной корреляции стран-членов ЕАЭС. При фрорсировании валютно-финансовой интеграции в ЕАЭС это обстоятельство будет постоянно препятствовать возникновению оптимальной модели взаимных расчётов с использованием коллективной валюты при условии устойчивого суверенного сосуществования [9; 16].

Целесообразность создания әффективной модели взаимных расчётов с использованием коллективной валюты при условии устойчивого суверенно-

1 Реестр препятствий / Портал общих информационных ресурсов и открытых данных / Функционирование общих рынков. URL: https://barriers.eaeunion.org/ru-ru/Pages/obstacles.aspx (дата обращения: 08.04.2021) 
Табл. 1. Корреляция динамики ИПЦ по ЕАЭС, 2020 г.

\begin{tabular}{|l|c|c|c|c|c|}
\hline \multicolumn{1}{|c|}{ Страны } & Россия & Белоруссия & Казахстан & Армения & Киргизия \\
\hline Россия & - & 0,6 & 0,3 & $-0,1$ & 0,5 \\
\hline Белоруссия & - & - & 0,2 & $-0,3$ & 0,8 \\
\hline Казахстан & - & - & - & 0,004 & 0,3 \\
\hline Армения & - & - & - & - & $-0,3$ \\
\hline Киргизия & - & - & - & - & - \\
\hline
\end{tabular}

Источник: составлено на основе International Monetary Fund / Principle Global Indicators

Табл. 2. Корреляция по ставке налога по доходам физических лиц в ЕАЭС, 2020 г.

\begin{tabular}{|l|c|c|c|c|c|}
\hline \multicolumn{1}{|c|}{ Страны } & Россия & Белоруссия & Казахстан & Армения & Киргизия \\
\hline Россия & - & $-0,3$ & $-0,3$ & 0,2 & -1 \\
\hline Белоруссия & - & - & 0,8 & $-0,6$ & 0,3 \\
\hline Казахстан & - & - & - & $-0,5$ & 0,3 \\
\hline Армения & - & - & - & - & $-0,2$ \\
\hline Киргизия & - & - & - & - & - \\
\hline
\end{tabular}

Источник: составлено на основе International Monetary Fund / Principle Global Indicators

Табл. 3. Корреляция по уровню средневзвешенной ставки по кредиту, 2020 г.

\begin{tabular}{|l|c|c|c|c|c|}
\hline \multicolumn{1}{|c|}{ Страны } & Россия & Белоруссия & Казахстан & Армения & Киргизия \\
\hline Россия & - & 0,8 & 0,7 & 0,7 & 0,8 \\
\hline Белоруссия & - & - & 0,5 & 0,9 & 0,9 \\
\hline Казахстан & - & - & - & 0,6 & 0,7 \\
\hline Армения & - & - & - & - & 0,9 \\
\hline Киргизия & - & - & - & - & - \\
\hline
\end{tabular}

Источник: составлено на основе International Monetary Fund / Principle Global Indicators

го сосуществования в рамках ЕАЭС может быть оценена на основе анализа финансовой результативности взаимных расчётов. По данным официальной статистики, Россия - основной внешнеторговый партнер Белоруссии, Казахстана, Армении, Киргизии [15]. По внешней видимости это говорит о широких возможностях использовать российский рубль во взаимных расчётах. Однако рубль подвержен сильной волатильности, играет слабую роль в торговле на международном валютном рынке, плохо представлен в официальных резервах [3].

Помимо корреляционного анализа степени конвергенции стран-членов ЕАЭС по макроэкономическим показателям, для оценки потенциала фрункционирования единой платежной системы ЕАЭС можно провести технический анализ динамики обменных курсов национальных валют стран ЕАЭС, главным образом тех из них, по которым существуют статистические данные биржевых торгов (сл. табл. 4). На Московской бирже проходят торги с участием трёх валют стран ЕАЭС: российским и белорусским рублями и казахскому тенге. По нашим расчётам, наибольшим образом коррелируют показатели российско-белорусского внешнеторгового оборота и торгов по валютной паре российский рубль/белорусский рубль на Московской бирже. Это означает, что в определенной мере есть потенциал введения конвертации, по крайней мере, 
Табл. 4. Показатели корреляции объёма взаимной торговли России, Белоруссии и Казахстана и торгами российским и белорусскими рублями и казахским тенге на Московской бирже в 2015-2020 гг.

\begin{tabular}{|c|c|c|c|c|c|}
\hline \multirow{2}{*}{ 뜽 } & \multirow{2}{*}{ 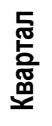 } & \multicolumn{2}{|c|}{ Россия $\leftrightarrow$ Казахстан } & \multicolumn{2}{|c|}{ Россия ↔ Белоруссия } \\
\hline & & Торги/Экспорт & Торги/Экспорт & Торги/Импорт & Торги/Импорт \\
\hline \multirow{4}{*}{$\stackrel{\text { م) }}{\stackrel{2}{2}}$} & 1 & 0,93 & 0,47 & 0,77 & 0,08 \\
\hline & 2 & 0,01 & 0,79 & 0,54 & 0,01 \\
\hline & 3 & 0,98 & 0,98 & 0,63 & 0,31 \\
\hline & 4 & 0,03 & 0,98 & 0,90 & 0,98 \\
\hline \multirow{4}{*}{$\stackrel{\circ}{\sim}$} & 1 & 0,49 & 0,07 & 0,21 & 0,92 \\
\hline & 2 & 0,21 & 0,79 & 0,27 & 0,98 \\
\hline & 3 & 0,01 & 0,53 & 0,94 & 0,34 \\
\hline & 4 & 0,15 & 0,87 & 0,67 & 0,05 \\
\hline \multirow{4}{*}{$\hat{\sim}$} & 1 & 0,38 & 0,28 & 0,40 & 0,54 \\
\hline & 2 & 0,81 & 0,82 & 0,44 & 0,90 \\
\hline & 3 & 0,77 & 0,92 & 0,85 & 0,34 \\
\hline & 4 & 0,82 & 0,12 & 0,36 & 0,39 \\
\hline \multirow{4}{*}{$\stackrel{\infty}{\grave{c}}$} & 1 & 0,97 & 0,58 & 0,81 & 0,97 \\
\hline & 2 & 0,00 & 0,99 & 0,94 & 0,66 \\
\hline & 3 & 0,95 & 0,42 & 0,25 & 0,50 \\
\hline & 4 & 0,98 & 0,73 & 0,95 & 0,96 \\
\hline \multirow{4}{*}{ 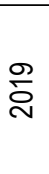 } & 1 & 0,08 & 0,98 & 0,90 & 0,88 \\
\hline & 2 & 0,54 & 0,07 & 0,21 & 0,90 \\
\hline & 3 & 0,28 & 0,79 & 0,27 & 0,88 \\
\hline & 4 & 0,21 & 0,53 & 0,84 & 0,54 \\
\hline \multirow{4}{*}{ ઠิે } & 1 & 0,18 & 0,77 & 0,77 & 0,35 \\
\hline & 2 & 0,48 & 0,38 & 0,50 & 0,64 \\
\hline & 3 & 0,71 & 0,72 & 0,54 & 0,80 \\
\hline & 4 & 0,78 & 0,88 & 0,60 & 0,41 \\
\hline
\end{tabular}

Источник: Московская биржа

российского и белорусского рублей в коллективную валюту при условии фрункционирования единой системы расчётов.

Для того чтобы создать эффрективно функционирующий механизм конвертации валют стран ЕАЭС, необходимо, по крайней мере, первоначально осуществлять торги ими не только на Московской бирже, но и на валютных биржах Белоруссии, Армении, Казахстана и Киргизии. Тем не менее даже с учетом наличия торгов на Московской бирже этого объёма явно недостаточно для того, чтобы опосредовать все внешнеторговые сделки России, Белоруссии и Казахстана, а потом и Армении и Киргизии, если армянский драм и киргизский сом начнут торговаться по валютным парам с валютами первых трех стран. Торги по валютам Армении и Киргизии на Московской бирже не проходят, что затрудняет получение полной картины корреляции и перспективы конвертации всех валют стран ЕАЭС в коллективную валюту. В связи с этим российский рубль - наиболее вероятная валюта расчётов в странах ЕАЭС на данном этапе, пока не сформировался и не отработан механизм конвертации в коллективную валюту, несмотря на то что его перспективы ограничены многими проблемами, связанными с экономическими и финансовыми затруднениями самой России, слабостью экономик других стран ЕАЭС, международными санкциями и т.д. [10]. 


\section{Инфраструктура потенциальной платежной системы ЕАЭС}

Одним из важнейших фракторов валютно-финансовой интеграции в странах ЕАЭС может стать формирование необходимой инфраструктурной базы для осуществления взаимных платежно-расчётных операций в круглосуточном режиме - Евразийской системы расчётов в круглосуточном режиме (ЕВРАСЧЁТ-24 ${ }^{2}$ ) - по образцу европейской системы ТАРГЕТ (TARGET2) ${ }^{3}$. ЕВРАСЧЁТ-24 работает при выполнении следующих обязательных условий:

1) наличие субъекта, предъявляющего требование на получение определенной суммы денег через коммерческий банк, расположенный в зоне евро;

2) наличие субъекта, готового выполнить это требование;

3) суверенное право пользования;

4) невмешательство в процесс распределения кредитных ресурсов;

5) беспрепятственный доступ к средствам любого кредитно-денежного института платежного союза;

6) реализация механизма беспрепятственной конвертации национальных валют стран.ЕАЭС в коллективную валюту, которая будет обращаться на уровне ЕВРАСЧЁТ-24;

7) использование искусственного интеллекта;

8) применение алгоритмов и роботов для организации торгов.

Коллективная валюта в условиях модели платежной системы EBPACЧЁТ-24 будет доступна в биржевых торгах только при условии использования современных технологий искусственного интеллекта и цифровизации, главным образом в фрорме роботизации биржевых торгов, алгоритмизации политики валютного курса, в рамках которой участники торгов будут иметь право выхода на валютный рынок только при посредничестве роботов и искусственного интеллекта [11]. Преимущество роботизации торгов коллективной валютой заключается в том, что, в отличие от людей, робот неукоснительно выполняет правила и законы кредитно-денежного и валютного регулирования. Такая валютная дисциплина торгов создаст возможность обеспечения устойчивости коллективной цифровой валюты, привлечёт капитал, заинтересованный в малорисковом, но стабильно и предсказуемо растущем доходе, сформирует экономическую стабильность и устойчивость роста ВВП, что будет отторгать горячий спекулятивный капитал, минимизирует отток и утечку капитала [12].

Некоторые обязательные требования функционирования EBPACЧЁТ-24 связаны с закономерным возникновением ряда проблем. Так, обязательность реализации этих условий, например, в ситуации долгового кризиса, означает, что во время кризиса ликвидности страна-член платежного союза может через систему ЕВРАСЧЁТ-24 самостоятельно оказать себе финансовую помощь, поскольку она продолжает функционировать, удовлетворяя все платежные и кредитные требования, несмотря на несостоятельность или дефолт. Сальдо, которое образуется при расчётах через систему ЕВРАСЧЁТ-24 в любых условиях, представляет собой бухгалтерскую запись в виде денежного требования к центральному банку страны-члена зоны коллективной валюты.

В нормальных условиях, когда имеют место трансграничные перечисления денежных средств из одной страны-члена в другую, например, между Россией и Казахстаном, то денежные потоки осуществляются в двух направлениях, то есть носят двусторонний характер, как в случае с товарно-денежными отношениями, предполагающими одновременное и встречное движение стоимости в натурально-вещественной и денежной формах труда. Так, если

2 В наименовании ЕВРАСЧЁТ-24 сочетается привязка к континенту (ЕВРАзия),. организация соответствующего типа отношений в рамках единой платежной системы (РАСЧЁТы), создание и депонирование необходимых ячеек учета всех операций (СЧЕТов), а также указание временной характеристики круглосуточного функционирования (24 часа в сутки).

3 TARGET (англ. Trans-European Real-time Gross-Settlement Express Transfer System трансъевропейская система валовых расчётов и денежных переводов в режиме реального времени) - это электронная региональная межбанковская система расчётов стран зоны евро и ЕC, созданная как аналог системы SWIFT, международной электронной системы расчётов. Впервые система TARGET заработала в 1996 г. Затем ввиду устаревания и необходимости учёта новых тенденций в сфере высоких технологий, скорости передачи данных, режима хранения конфиденциальной банковской информации она уступила место системе TARGET2 в ноябре 2007 г. 
гражданин Казахстана приобретает автомобиль в России, то система EBPACЧЁТ-24 организует перечисление денежных средств на счет компании-дилера или производителя данного автомобиля. Для перечисления центральный банк Казахстана обращается к Банку России с требованием от своего имени выплатить автопроизводителю требуемую сумму денег.

Система ЕВРАСЧЁТ-24 не требует физической доставки денег. В ситуации, когда российский коммерческий банк выдает кредит гражданину Казахстана, Банк России обращается к центральному банку Казахстана с требованием - от своего имени предоставить указанному субъекту кредит. Во время кризиса данная операция не производится, так как денежный перевод в Казахстан происходит без участия частных лиц. В этом случае перечисление денег из Казахстана в Россию возможно только в порядке погашения долга. Тем самым Банк России предоставляет казахскому центральному банку нетто-кредит. Банк России исполняет денежные переводы от своего лица по поручению центрального банка Казахстана, и эти денежные средства поступают на счета поставщиков товаров и услуг и российских коммерческих банков, которые требуют погашения кредитов, выданных гражданам Казахстана, и бухгалтерская операция по списанию счетов проводится не через центральный банк Казахстана, а через Банк России.

В результате возникают долговые отношения между обоими центральными банками, которые выражаются в следующем: Банк России имеет требование к казахскому центральному банку, а последний - долг по отношению к первому. И на основании этого образуется сальдо в отчетности системы ЕВРАСЧЁТ-24. В экономической теории такое сальдо определяется как сальдо платежного или торгового баланса. При трансграничном перемещении капитала такое сальдо учитывается в платежном балансе. Если в этом случае из Казахстана, Кыргызстана, Армении передаются поручения по сальдо платежного баланса в Россию, то отсутствуют необходимые денежные средства, поскольку с каждым реализованным платежным поручением происходит самоуничтожение денег в первых странах. В результате в обращении уменьшается количество денег. И тогда, если в Россию осуществляется нетто-поток денежных средств, он уничтожается в течение нескольких месяцев.

Для предотвращения такого несоответствия или отклонения денежной массы от плановых величин единый клиринговый центр в процессе перемещения денег из Белоруссии, Казахстана, Кыргызстана, Армении в Россию запускает механизм автоматического создания новых денег через соответствующие кредиты центральных банков ЕАЭС. При этом в сальдо системы ЕВРАСЧЁТ-24 учитываются не только нетто-перечисления через систему центральных банков, но и создание новых денег в Белоруссии, Казахстане, Кыргызстане, Армении для компенсации оттока ликвидности. Так, дополнительно созданные Банком России деньги российские коммерческие банки вновь перечисляют на счёт центрального банка, и тем самым они изымаются из обращения. В Банке России происходит квази-уничтожение денежной массы $^{4}$, то есть в Белоруссии, Казахстане, Кыргызстане, Армении производится эмиссия коллективной валюты, а в России - их уничтожение (шредирование). Учёт объёма шредирования денежной массы в России осуществляется также в системе ЕВРАСЧЕТ-24 и отражается в соответствующем сальдо. С учётом опыта фрункционирования европейской системы ТАРГЕТ2 расширение этого сальдо приводит к серьезным проблемам задолженности отдельных стран зоны евро 5 .

4 Квази-уничтожение денежной массы (от лат. quasi - почти, как бы, не по-настоящему) представляет собой процесс стерилизации инфляционного расширения кредитной массы, а стерилизация означает перевод этих кредитных денег в специальные фонды, которые блокируют их дальнейшую мультипликацию в экономической системе, когда первоначально созданное количество денег умножается на денежный мультипликатор, величина которого обратно пропорциональная норме обязательного резервирования центрального банка. Норма обязательного резервирования требует от коммерческих банков содержать определенную сумму денег на беспроцентном счёте центрального банка на случай форс-мажорного увеличения потребности в ликвидных средствах со стороны различных экономических субъектов.

5 Согласно данным учёта системы ТАРГЕТ2, эмиссия евро в таких проблемных странах, как Греция, Испания, Ирландия, Италия, Португалия и Кипр, в результате применения опи- 


\section{Выводы}

Система ЕВРАСЧЁТ-24 по существу, на основе своих принципов, исключает возможность и вероятность банкротства или дефолта отдельного государства-участника валютно-фринансовой интеграции, поскольку этого требует соблюдение условия устойчивого суверенного развития. В каждой стране ЕАЭС, скорее всего, будет продолжать функционировать национальный центральный банк, которому будет предоставлено право допечатывать коллективную валюту в форс-мажорных ситуациях, поэтому фиаско государства фрактически невозможно. Создание такой уверенности и надежности долговых ценных бумаг будет приводить к оттоку капитала из России в остальные страны ЕАЭС. После преодоления различий в уровнях процентных ставок для стран ЕАЭС будут созданы благоприятные условия финансирования. Это, в свою очередь, вызовет рост долгов, совокупных расходов домохозяйств и подготовит почву для инфляционного экономического бума ${ }^{6}$ и пузыря. Этот инфляционный пузырь может лопнуть и спровоцировать долговой кризис и кризис коллективной валюты по образцу зоны евро.

В ситуации кризиса единому клиринговому центру и Банку России придётся вмешиваться и продолжать вместо частных кредиторов фоинансировать торговый и платежный баланс остальных стран ЕАЭС. Им вновь будут предложены суммы кредитов на выгодных условиях за счёт новой эмиссии коллективной валюты. Однако ввиду кризиса в этих странах частные инвесторы могут отказать им в новых кредитах, и начнется отток капитала. Тогда проблемным странам ЕАЭС придётся погашать отзываемые кредиты за счёт новой эмиссии коллективной валюты, что будет отражаться в сальдо системы ЕВРАСЧЁТ-24. В результате усилится вероятность углубления кризиса валютно-фринансового союза ЕАЭС.

Опираясь на опыт зоны евро, наднациональному клиринговому центру ЕАЭС и Банку России нужно формировать Евразийский механизм финансовой стабильности, который будет функционировать по принципу организации фондов финансовой стабильности на общепринятых условиях предоставления финансовой помощи и кредитов.

\section{Литература}

1. Алексеев П.В., Звонова Е.А. Развитие концептуальной модели формирования общего финансового рынка государств - членов Евразийского экономического союза // Банковское право. 2020. № 4. С. 44-51.

2. Быстров А.В., Быстрова Д.А., Юсим В.Н. Справедливость и безопасность межгосударственных взаимных расчётов в рамках интегрированных объединении государств // Вестник РАЕН. 2017. Т. 17. № 1. С. 70-74.

санного механизма объём кредитования к 2020 г. достиг 1871 млрд евро. Данное кредитное расширение началось с лета 2007 г., когда в США произошел обвал рынка ипотечного капитала. До 2007 г. сальдо по трансакциям в системе ТАРГЕТ составляло 0, то есть имел место баланс трансграничного движения капитала. В страновом разрезе образовавшееся непогашенное сальдо приходится в основном на Германию, Люксембург, Нидерланды, Финляндию. Эти четыре страны смогли предоставить кредиты через систему ТАРГЕТ2 за счёт положительного сальдо торгового и платежного баланса со странами остального мира. При этом главными получателями этих кредитов являются Испания, Италия, Греция, Португалия.

6 Инфляционный экономический бум представляет собой высокие темпы экономического роста, достигнутые, как правило, не за счет роста реального производства, а главным образом - в результате роста цен на различные финансовые инструменты и активы, включая жилищный капитал. В свою очередь, бум означает высшую точку әкономического развития в рамках одного экономического цикла. Бум закономерно вызывает перегрев в экономике, провоцируя кризис и депрессию. Перегрев экономики состоит в том, что в результате интенсивного развития экономики и инфляционного роста цен дополнительное привлечение фракторов производства (труда, земли, капитала) становится невозможным, поскольку экономика вышла на кривую трансформации (кривую своих производственных возможностей) и находится в условиях полной занятости, то есть фракторы производства дефицитны и взять их неоткуда (в закрытой системе). В случае открытой экономики факторы производства для дальнейшего экономического бума можно взять только в кредит на международном рынке, что закономерно означает рост государственного долга перед нерезидентами. 
3. Гаврилов Н.В., Прилепский И.В. Рубль как валюта международных расчётов: проблемы и перспективы // Вопросы экономики. 2017. № 6. С. 94-113.

4. Глазьев С.Ю. Об использовании цифровых технологий в целях создания рынка капитала ЕАЭС // Евразийская интеграция: экономика, право, политика. 2018. № 1 (23). C. $7-8$.

5. Гончаренко М.А., Хомякова Л.И. Формы валютных и платежно-расчётных отношений и перспективы их применения в рамках ЕАЭС // Деньги и кредит. 2015. № 9. C. $27-33$.

6. Достов В.Л., Шуст П.М., Алексеев Г.В., Криворучко С.В. Подходы к регулированию рынка электронных денег на пространстве ЕАЭС: сравнительный анализ // Финансовый журнал. 2020. Т. 12. № 5. С. 43-58.

7. Звонова Е.А., Кузнецов А.В., Пищик В.Я., Сильвестров С.Н. Особенности и перспективы построения двухконтурной валютно-финансовой системы на национальном и региональном уровне // Мир новой экономики. 2020. Т. 14. № 1. С. 26-33.

8. Крохина Ю.А. Правовые основы и перспективы развития Евразийского экономического союза как валютного союза // Юридическая наука. 2018. № 4. С. 21-24.

9. Кудрявцева Л.Н. Институт центрального контрагента на финансовом пространстве ЕАЭС // Банковское дело. 2017. № 2. С. 50-56.

10. Кузнецов А.В. Региональная роль Евразийского банка развития в посткоронавирусном мире // Мир новой экономики. 2020. Т. 14. № 4. С. 22-32.

11. Логинов Е.Л., Григорьев В.В., Романова Ю.А., Борталевич В.Ю. Проблемы упорядочения оборота криптовалют как базы для наращивания инвестиций с учетом перспективной интеграции финансовых систем в рамках ЕАЭС // Образование. Наука. Научные кадры. 2019. № 1. С. 111-116.

12. Мишина В.Ю., Хомякова Л.И. Дедолларизация и расчёты в национальных валютах: евразийский и латиноамериканский опыт // Вопросы экономики. 2020. № 9. C. $61-79$.

13. Петрушевская А.В. Укрепление торгово-экономического сотрудничества государств-членов ЕАЭС с последующим введением пределов взаимных колебаний национальных валют государств-членов ЕАЭС как средство развития ЕАЭС // Colloquiumjournal. 2019. № 10-8 (34). C. 124-129.

14. Сибирская А. Снижение экономических рисков за счет эффектов валютной интегращии стран - членов ЕАЭС // Банковский вестник. 2019. № 1 (666). С. 55-62.

15. Степанов Н.С. Переход на национальные и другие валюты в рамках создания новой модели развития России // Бизнес. Образование. Право. 2021. № 1 (54). С. 169174 .

16. Шевченко И.В., Коробейникова М.С. Новая универсальная валюта для международных расчётов - "условная денежная единица" // Экономика: теория и практика. 2020 . № 2 (58). C. 3-16.

\section{Транслитерация по ГОСТ 7.79-2000 Система Б}

1. Alekseev P.V., Zvonova E.A. Razvitie kontseptual'noj modeli formirovaniya obshhego finansovogo rynka gosudarstv - chlenov Evrazijskogo ehkonomicheskogo soyuza // Bankovskoe pravo. 2020. № 4. S. 44-51.

2. Bystrov A.V., Bystrova D.A., YÚsim V.N. Spravedlivost' i bezopasnost' mezhgosudarstvennykh vzaimnykh raschyotov $\mathrm{v}$ ramkakh integrirovannykh ob"edinenii gosudarstv // Vestnik RAEN. 2017. T. 17. № 1. S. 70-74.

3. Gavrilov N.V., Prilepskij I.V. Rubl' kak valyuta mezhdunarodnykh raschyotov: problemy i perspektivy // Voprosy ehkonomiki. 2017. № 6. S. 94-113.

4. Glaz'ev S.YU. Ob ispol'zovanii tsifrovykh tekhnologij v tselyakh sozdaniya rynka kapitala EAEHS // Evrazijskaya integratsiya: ehkonomika, pravo, politika. 2018. № 1 (23). S. 7-8.

5. Goncharenko M.A., KHomyakova L.I. Formy valyutnykh i platezhno-raschyotnykh otnoshenij i perspektivy ikh primeneniya v ramkakh EAEHS // Den'gi i kredit. 2015. № 9. S. 27-33.

6. Dostov V.L., SHust P.M., Alekseev G.V., Krivoruchko S.V. Podkhody k regulirovaniyu rynka ehlektronnykh deneg na prostranstve EAEHS: sravnitel'nyj analiz // Finansovyj zhurnal. 2020. T. 12. № 5. S. 43-58.

7. Zvonova E.A., Kuznetsov A.V., Pishhik V.YA., Sil'vestrov S.N. Osobennosti i perspektivy postroeniya dvukhkonturnoj valyutno-finansovoj sistemy na natsional'nom i regional'nom urovne // Mir novoj ehkonomiki. 2020. T. 14. № 1. S. 26-33.

8. Krokhina YU.A. Pravovye osnovy i perspektivy razvitiya Evrazijskogo ehkonomicheskogo soyuza kak valyutnogo soyuza // YUridicheskaya nauka. 2018. № 4. S. 21-24.

9. Kudryavtseva L.N. Institut tsentral'nogo kontragenta na finansovom prostranstve EAEHS // Bankovskoe delo. 2017. № 2. S. 50-56.

10. Kuznetsov A.V. Regional'naya rol' Evrazijskogo banka razvitiya v postkoronavirusnom mire // Mir novoj ehkonomiki. 2020. T. 14. № 4. S. 22-32. 
11. Loginov E.L., Grigor'ev V.V., Romanova YU.A., Bortalevich V.YU. Problemy uporyadocheniya oborota kriptovalyut kak bazy dlya narashhivaniya investitsij s uchetom perspektivnoj integratsii finansovykh sistem v ramkakh EAEHS // Obrazovanie. Nauka. Nauchnye kadry. 2019. № 1. S. 111-116.

12. Mishina V.YU., KHomyakova L.I. Dedollarizatsiya i raschyoty v natsional'nykh valyutakh: evrazijskij i latinoamerikanskij opyt // Voprosy ehkonomiki. 2020. № 9. S. 6179 .

13. Petrushevskaya A.V. Ukreplenie torgovo-ehkonomicheskogo sotrudnichestva gosudarstv-chlenov EAEHS s posleduyushhim vvedeniem predelov vzaimnykh kolebanij natsional'nykh valyut gosudarstv-chlenov EAEHS kak sredstvo razvitiya EAEHS // Colloquium-journal. 2019. № 10-8 (34). S. 124-129.

14. Sibirskaya A. Snizhenie ehkonomicheskikh riskov za schet ehffektov valyutnoj integratsii stran - chlenov EAEHS // Bankovskij vestnik. 2019. № 1 (666). S. 55-62.

15. Stepanov N.S. Perekhod na natsional'nye i drugie valyuty v ramkakh sozdaniya novoj modeli razvitiya Rossii // Biznes. Obrazovanie. Pravo. 2021. № 1 (54). S. 169-174.

16. SHevchenko I.V., Korobejnikova M.S. Novaya universal'naya valyuta dlya mezhdunarodnykh raschyotov - "uslovnaya denezhnaya edinitsa" // EHkonomika: teoriya i praktika. 2020. № 2 (58). S. 3-16.

Жариков М. В. Потенциал функционирования платежно-расчётной системы в рамках ЕАЭС и обращения коллективной валюты.

Тема исследования актуальна в связи с эскалацией международных санкций в отношении России и вероятностью её исключения из расчётной системы SWIFT. Поскольку другие страны ЕАЭС находятся в сильной зависимости от России в сфере внешней торговли, инвестиций, обмена технологиями, транспорта, энергетики и т.д., подобные санкции оказывают существенное дестабилизирующее влияние и на них. C учётом этих тенденций и зарубежного опыта автор делает попытку сформулировать основные әлементы и направления создания независимой системы расчётов стран ЕАЭС с оценкой перспектив использования коллективной валюты, повышения уровня независимости экономик от колебаний мировых цен, преодоления зависимости от доллара.

Ключевые слова: платежная система ЕВРАСЧЁТ-24, коллективная региональная валюта ЕАЭС, межстрановая дивергениия, фбакторы и условия валютно-фбинансовой интеграции, барьеры интеграции

Zharikov M. V. The potential of a regional settlement system and a collective regional currency for the EAEU.

The topic of the research is time-relevant due to intensifying international sanctions against Russia and a possibility of its exclusion from the world settlement system SWIFT. Since the rest of the EAEU heavily depends on Russia in terms of foreign trade, investment, technology exchange, transport, energy, etc., such sanctions are drastically damaging and economically destabilizing for everyone in the EAEU. Taking into account this experience and world expertise, the author makes an attempt to formulate basic elements and principles of creating an independent payment system for the EAEU and estimate a prospective use of a collective currency, further and deeper independence from world prices fluctuations and break away from the dollar.

Key words: payment system EURACCOUNT-24, collective regional currency for the EAEU, inter-country divergence, factors and conditions of currency and financial integration, integration barriers

Для цитирования: Жариков М. В. Потенциал функционирования платежно-расчётной системы в рамках ЕАЭС и обращения коллективной валюты // Ойкумена. Регионоведческие исследования. 2021. № 4. C. 78-86. DOI: 10.24866/1998-6785/2021-4/78-86

For citation: Zharikov M. V. The potential of a regional settlement system and a collective regional currency for the EAEU // Ojkumena. Regional researches. 2021. № 4. P. 78-86. DOI: $10.24866 / 1998-6785 / 2021-4 / 78-86$ 